\title{
THE IMPACT OF WORK INVESTMENT ON PERFORMANGE
}

\author{
Cătălina Radu ${ }^{1}$, Alecxandrina Deaconu ${ }^{2}$, Sorina Ioana Mișu ${ }^{3}$ \\ and Monica Triculescu ${ }^{4 *}$ \\ 1213)4) University of Economic Studies, Bucharest, Romania
}

\section{Please cite this article as:}

Radu, C., Deaconu, A., Mișu, S.I. and Triculescu, M., 2020. The Impact of Work Investment on Performance. Amfiteatru Economic, 22(Special Issue No. 14), pp. 1103-1120

DOI: $10.24818 / \mathrm{EA} / 2020 / \mathrm{S} 14 / 1103$

\section{Article History}

Received: 29 June 2020

Revised: 25 August 2020

Accepted: 30 September 2020

\begin{abstract}
The paper's main objective is to analyse the impact of work investment on performance. The research involved administering an online questionnaire, which collected information on work effort, perceived performance, burnout and job satisfaction. The study was conducted on a group of 313 participants, all active on the labour market - employees (with or without management position) and entrepreneurs in various fields of activity. Sampling was unlikely, based on the availability criterion. The results obtained claim that the perception of performance mediates the relationship between effort at work and satisfaction obtained through work itself, and burnout is moderate both in the relationship between effort and perception of performance, and in that between perception of performance and satisfaction through the work itself. Consistent with the literature and within the limits of the methodology used, it has been found that management functions are associated with a lower level of burnout than others, a greater power in decision-making means an increased ability to detach from problems, even if the investment in labour is appreciable.
\end{abstract}

Keywords: investment in work, effort, performance, job satisfaction, burnout

JEL Classification: M12, M54, D91

* Corresponding author, Monica Triculescu - e-mail: monica.triculescu@ man.ase.ro 


\section{Introduction}

The concern for performance is an essential coordinate of the world we live in with an increased emphasis on valuing people's work. Of course, we are not all the same in terms of time spent working, intensity, direction and perseverance of the effort, and quantifying investment in work proves to be a challenge. Intuitively, or based on our experience, we know that this investment leads to more, in terms of results. Sometimes, however, more becomes too much, and crossing this threshold causes negative implications for organizational performance.

Based on these aspects and on many studies that support the role of job satisfaction as a predictor of the organization's performance, we aimed to analyse how the effort made by people in their professional activity influences job satisfaction and thus performance. We also aimed to analyse the extent to which the phenomenon of burnout influences both the relationship between effort and perceived performance, as well as between performance and job satisfaction.

In essence, the aim of our paper is to highlight the scientific significance of investing in work and its relationship with the employee's performance and to offer support for managers concerned with better staff retention, changing the perception that work is a cost rather than an investment, achieving superior organizational performance.

In line with the paper's aim, the article was structured into two parts: in the first part we clarify the main concepts regarding work investment, work performance, work satisfaction, the burnout phenomenon and the relationships between all of them and in the second part, we present our research regarding the impact of work investment on performance.

\section{Investment in work and performance - Conceptual aspects}

\subsection{What does work investment mean?}

The concept of work investment has prevailed in literature, especially after Snir and Harpaz (2011) analysed four elements: massive investment in labour, its possible predictors, its types and results. According to the authors, the concept integrates the notion of workaholism defined by Snir and Zohar (2008) as a massive investment of time in work, which does not occur as a result of external financial requirements.

However, investing in work is not synonymous with workaholism. Shimazu, Schaufeli, Kamiyama and Kawakam (2014) analysed two major dimensions of investment in work: one related to wear (workaholism) and another related to involvement (work engagement). Thus, the authors showed that the first component is a good predictor of stress and health problems, while the second leads to higher long-term satisfaction and performance.

Likewise, Van Beek et al. (2013) showed that workaholism is negatively correlated with job satisfaction, performance and intention to leave the job, while work engagement is positively correlated with job satisfaction and performance and negatively with the intention of leaving work. Both sides of investing in work are important.

In this paper we mainly analyse the effects of work engagement on performance. In order to take into account, the negative side of investing in work, we also present the burnout 
phenomenon and follow its effects. It should be noted that recent studies indicate that there is not necessarily a negative correlation between burnout and involvement (Kuok and Taormina, 2017). The authors give as an example the teachers who might at some point feel the burnout due to overload, at the same time being very dedicated and satisfied with their achievements. We consider this to be very important, as until recently most guidelines said that burnout and work involvement are distinct ends of the same continuum, and therefore, the higher the burnout, the lower the work involvement and vice versa (Maslach, Jackson and Leiter, 1997).

\subsection{The burnout phenomenon}

In psychology, burnout syndrome or professional exhaustion syndrome is a state of exhaustion, both physical and mental, which occurs especially in people whose profession involves a special responsibility and frequent interactions with people. It occurs more and more frequently in the modern era and leads to decreased performance at the workplace, it affects relationships with others and the individual's quality of life. Freudenberger (1980) described in details this disorder. Later, Maslach and Jackson (1982) defined burnout as a state of physical, emotional, and mental exhaustion, coupled with cynicism toward individual work in response to the action of factors that cause chronic stress. After that, Maslach, Jackson and Leiter (1997) conceptualized burnout as the situation that manifests itself by changing attitudes and work-related behaviour through physical, mental, and emotional exhaustion that generates low personal success.

According to Leatz and Stolar (1993), burnout is the physical, emotional, and mental exhaustion caused by long-term involvement in emotionally demanding and stressful situations, coupled with very high personal expectations about one's own performance.

The workplace tends to be the most conducive environment for the development of this condition, but there are situations in which social or personal life lead to burnout. People affected by burnout can have a negative impact on their co-workers, both by creating conflicts and by interrupting work tasks. There are also studies which show that burnout has a negative impact on the personal life of individuals (Bakker, 2009; Burke and Greenglass, 2001).

Maslach, Schaufeli and Leiter (2001) consider that the manifestation of burnout is in the form of three key dimensions:

- emotional exhaustion - the state of feeling drained of inner resources; this is the basic dimension of individual stress;

- depersonalization / cynicism - cynical and distant attitude towards work and coworkers; this is the interpersonal context in which burnout occurs and indicates attitudes such as lack of involvement and lack of enthusiasm;

- low personal success - the tendency of the individual to evaluate their success at work in a negative way; this dimension is the component of self-assessment of burnout.

Gorji (2011) showed that burnout has a negative impact on work performance, through the first two components (exhaustion and depersonalization) and less through the tendency to underestimate successes. 


\subsection{Effort, performance and satisfaction}

Effort concerns have sought to highlight new ways in which it can be amplified to increase performance. Effort, also known under the name of endeavour or striving, can be defined as a voluntarily focus, a mobilization of physical and psychological strengths in order to obtain a superior productivity than the usual one or in order to overcome a main challenge. The interest for this concept is explained by the fact that the human being, seen as a source of effort and as a gainer of satisfaction, is considered to be the performance creator. Therefore, our interest into measuring the effort and assessing its associated effects comes naturally

Involvement in work does not only refer to behaviours, but also to thoughts and emotions (Kuok and Taormina, 2017). Hence, De Cooman, De Gieter, Pepermans, Jegers and Van Acker (2009) developed a tool based on three dimensions, applicable regardless of the respondents' field of activity:

- perseverance - expresses the duration of the work submitted by a person and the determination with which he tries to successfully complete the chosen work;

- direction - shows what the person is doing, but also the behaviour that the individual chooses to have within the organization;

- intensity - expresses the level of depth at which the person works, as well as the extent to which he strives to complete a task.

Greater involvement should also mean higher performance, if we consider, for example, motivation based on goal setting, a theory which states that a higher motivation is based on four principles in goal setting, all of which showing involvement (Locke and Latham, 1985):

- Difficulty - Challenging goals lead to superior performance compared to easy-toachieve goals;

- Specificity - Specific objectives are more effective than general ones;

- Assumption - In order to be achieved, goals must be accepted, regardless of whether they are assumed or set by someone else;

- Feedback - Objectives do not lead to results in the absence of feedback. In this regard Bandura (1986) emphasizes that short-term goals are the safest, because the assessment of success in their case is more accurate.

There are also studies that have shown a negative influence of effort on job satisfaction (Christen, Iyer, and Soberman, 2006). However, their authors draw attention to the need to clearly define the constructs, as it is natural that different facets of the same dimension lead to different results.

In terms of performance, it is used as a working variable in many researches, but the conceptualization of this notion is not universal. Regardless of the meaning, a distinction must be made between an action and an outcome (Campbell, et al., 1993; Roe, 1999; Sonnentag and Frese, 2002).

The concept of performance involves an evaluation process (Motowidlo, Borman, and Schmit, 1997). Sonnentag and Frese (2002) come up with examples to support this idea: the teacher who presents the lesson excellently but does not get results because students have, 
for various reasons independent of him, a mind oriented towards something else, or a sales agent who does not work too much, but sells easily due to existing market demand.

Motowidlo and Scotter (1994) talk about the existence of two dimensions of the concept of employee performance:

- workload performance - or "technical performance";

- contextual performance - or "interpersonal performance".

According to Bourguignon (1997), the concept of employee job performance refers to the achievement of organizational goals and can be viewed from three perspectives:

- the successful outcome of an action or even the action itself;

- the ability to remain in a permanent dynamic state, due to constant effort;

- representation of an ideology of progress, effort, permanent desire for improvement.

It is widely accepted that the success of the organization depends primarily on the performance of employees, so one of the main organizational objectives is to increase their performance. The concern to measure the actual or perceived level of performance has led to the design and use of a significant number of assessment tools. Griffin, Neil and Parker (2007), propose a tool based on three different subdimensions of work performance:

- the level of competence - which we can say that shows the extent to which an individual fulfils his formal work tasks;

- adaptability - which indicates the extent to which an individual responds to changes related to his job or responsibilities;

- proactivity - which describes how the individual acts on their own to anticipate or initiate changes at the organizational level or related to their work responsibilities.

To the same extent, the instrument aims to measure the perception of the level of performance at work on three levels in which the individual manifests himself: at individual level, at team level and at organizational level. Thus, the proposed model becomes a matrix with nine elements that investigate each sub-dimension of performance on each of the three levels.

The next important construct for our work is job satisfaction, in fact one of the most researched concepts in the field of human resources and organizational psychology, it is defined as the extent to which people like (satisfaction) or dislike (dissatisfaction) the work which they do (Spector, 1997).

A satisfied employee in terms of his work is more efficient and productive (Pushpakumari, 2008). Also, job satisfaction favours reducing absenteeism and increasing employee retention rate (Griffeth, et al., 2000; Karatepe, et al., 2006; Posada, et al., 2017). Studies show that the level of job satisfaction is positively correlated with productivity ( Spector, 1997, Judge, et al., 2001). However, some research has shown that although the correlation between performance and satisfaction exists and is a positive one, it is quite poor and it is not clear whether performance makes people more satisfied with their work, or whether this satisfaction is decisive in obtaining performance (Bakotić, 2016). 
Job satisfaction is the result of employees' perception of the extent to which work provides them with the elements they consider important in their lives. Job satisfaction is an emotional response to a professional context, often determined by the extent to which the results obtained meet or even exceed the individual's expectations (Luthans, 1998).

\subsection{Studies that analyse the work investment - between performance and burnout}

All the above presented studies are directly related to the purpose of our research and to the used methodology. However, we consider that there are some studies which deserve a special approach in this section. Thus, the research of Ajzen (2011), Job satisfaction, effort, and performance: A reasoned action perspective, drew our attention, which is an in-depth study of the relevant literature in the field, exactly for the main variables taken into account by us: effort, performance and job satisfaction. The author argues for the shift from an emphasis on job satisfaction to an attitude that takes into account the proximal antecedents of effort and performance. Based on the theory of planned behaviour, we can identify three factors that guide people's decisions or intentions to make an effort at work attitudes towards this behaviour, perceived social pressure to make or, conversely, not to make this effort (subjective rules) and perceptions in the sense of self-evaluation of results in relation to the effort made. The same three variables can be considered when analysing workplace performance. In this case, however, we must keep in mind that performance is not a behaviour, but rather a possible result of various behaviours related to the effort. Attitudes, subjective norms and perceptions about the real possibility of influencing the level of performance are manifested in the form of intentions that may be affected by environmental constraints; thus, ideally, only the elements that belong exclusively to the employee in terms of achieving the intended result should be taken into account and other factors should be eliminated. This conclusion led us to reconsider the role of performance as a mediating factor in the relationship effort-job satisfaction.

Another study that considers the idea proposed by us is the one conducted by Brown and Peterson (1994), The effect of effort on sales performance and job satisfaction. The conclusion of this research is different, namely that effort has a direct effect on job satisfaction, regardless of sales performance. Thus, starting from the idea that people have a real need to feel that they are doing things, the authors found, analysing a batch of 360 sales agents in the United States, that effort in work has a direct effect on satisfaction, effect that is not mediated by sales performance. The authors extended the model to verify whether this is typical of this field of activity and concluded that this result can be generalized.

Moving to another facet of investment in work, the phenomenon of burnout, our attention was drawn by Woo, Park and Kim (2017) in their study Job satisfaction as a moderator on the relationship between burnout and scholarly productivity among counseling faculty in the U.S. The authors found, on a group of 251 participants, that job satisfaction is moderating in the relationship between burnout and productivity, thus emphasizing, once again, the role of job satisfaction in achieving organizational performance. Given that the phenomenon of burnout also has different causes of professional life, we consider it useful to address the problem and vice versa, i.e. to follow the extent to which burnout plays the role of moderator in the relationship between effort and perception of performance, as well as in the relationship between perception of performance and job satisfaction. 
Another interesting element concerns the differences between those who hold management positions and those who do not hold such positions. Even if managers are expected to have a serious load on the program, they are considered less susceptible to burnout, as managerial decision-making and implicitly their decision-making power means a greater ability to influence situations in a manner considered favourable. In his 2005 study, Overcoming job burnout: how to renew enthusiasm for work, Potter claims that this ability gives managers a slightly greater detachment from negative organizational aspects (Potter, 2005).

\section{Study regarding the impact of work investment on performance}

\subsection{Research objectives and hypotheses}

This research has as a general objective the analysis of the work investment's impact on performance, highlighting the relationships between work effort, perception of performance, job satisfaction and the phenomenon of burnout.

From the general objective derive a series of secondary objectives:

- evaluation of the level of effort made in the work, seen as perseverance, direction and intensity;

- identifying the perception regarding work performance (competence, adaptability and proactivity);

- assessing the level of job satisfaction;

- measuring perceived burnout;

- analysis of the differences between managers and non-managers regarding the perceived burnout;

- identifying the relationships between all these above variables;

- outlining proposals based on which to increase organizational performance, with employees more satisfied with their own work and with low intentions to leave the job.

Thus, we propose a model of the relationship between the four variables (figure no. 1).

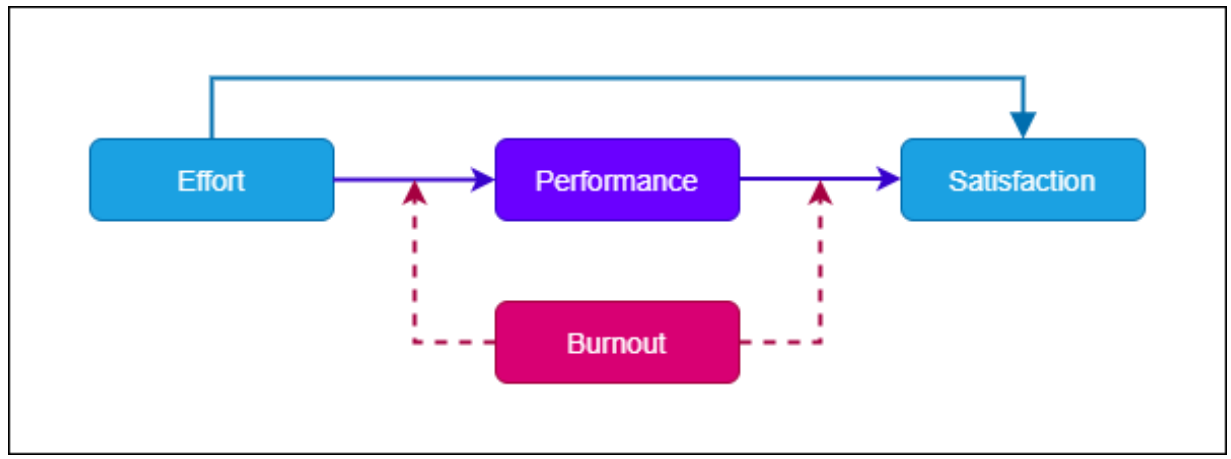

Figure no. 1. The influence of burnout on the relationship effort-performance-satisfaction 
Our model considers the perceived performance as a mediating variable between effort and satisfaction, and the burnout phenomenon as a moderating variable within two relationships (effort - perceived performance and perceived performance - satisfaction).

As a result, for this paper we proposed four working hypotheses:

- Hypothesis 1. Perception of performance mediates the relationship between work effort and job satisfaction

- Hypothesis 2. Burnout moderates the relationship between effort and the perception of performance.

- Hypothesis 3. Burnout moderates the relationship between perception of performance and satisfaction obtained through work itself.

- Hypothesis 4. If participants hold a leadership position, then the level of burnout is lower than if the participants do not hold leadership positions

\subsection{Research methods and tools}

The study was conducted on a group of 313 participants. We used nonprobability sampling, based on the availability criterion. 193 of the respondents $(61.67 \%)$ are females, and 120 $(38.33 \%)$ are males. In terms of age, participants are between 20 and 63 years old, with a mean age of 33.2 (standard deviation being 11.7). Participants are part of private and public organizations and are employees (with or without management positions) and entrepreneurs (table no. 1).

Table no. 1. Data about respondents

\begin{tabular}{|l|r|r|l|r|r|}
\hline \multicolumn{3}{|c|}{ Form of ownership } & \multicolumn{3}{c|}{ Status on the labour market } \\
\hline Organization & Counts & \% of Total & Status & Counts & \% of Total \\
\hline Private & 217 & 69.33 & Employed & 206 & 65.81 \\
\hline Public & 96 & 30.67 & Entrepreneur & 23 & 7.35 \\
\hline & & & Manager & 84 & 26.84 \\
\hline Total & 313 & 100 & Total & 313 & 100 \\
\hline
\end{tabular}

The research was based on the use of four scales taken from Research Central, with the corresponding statements and respecting the scoring method (the way of grading using scales associated with the testing tools) (http://www.researchcentral.ro/index.php?action= listateste).

The work effort scale - 534 (Research Central) - includes 10 items and measures the perseverance, direction and intensity of the effort. The internal consistency coefficient Cronbach's alpha of the Workplace Scale is 0.972 .

Griffin's Workplace Performance Scale - 431 (Research Central) - includes 27 items and measures competence, adaptability and proactivity in performing individual tasks, as a member of a team and in an organization in general. The internal consistency coefficient Cronbach's alpha of the Griffin Workplace Performance Scale is 0.962. 
Maslach's inventory for measuring burnout - 412 (Research Central) - includes 16 items, grouped into three categories - Exhaustion, Cynicism and Professional Inefficiency - the separation into the three categories is not the subject of this paper, for which we considered the level total of this indicator. The internal consistency coefficient Cronbach's alpha of the Maslach burnout measurement inventory is 0.931 .

Job Satisfaction - We used only one subscale from the Job Satisfaction Assessment Questionnaire, scale 396 (Research Central) to measure it. The questionnaire includes a total of 36 items, of which 19 are reversed (with inversed scoring). One of the subscales measures job satisfaction in itself (the nature of the work) and, unlike the other subscales, it can also be tracked as a result of the effort made and the results obtained as a result of this effort. The internal consistency coefficient Cronbach's alpha of the Satisfaction by nature of work subscale is 0.837 .

No items were removed from any of the four scales used.

\subsection{Processing and presentation of research data}

Data are not normally distributed for any of the four variables considered. In the case of the Performance variable, the skewness and kurtosis indicators are in the range $[-0.7 ;+0.7]$, but the Shapiro-Wilk test indicates a non-parametric distribution (table no. 2). As a result, we use non-parametric methods to test hypotheses.

Table no. 2. Descriptive data for the four variables

\begin{tabular}{|l|r|r|r|r|}
\hline & Work effort & Performance & Burnout & Satisfaction \\
\hline N & 313 & 313 & 313 & 313 \\
\hline Mean & 59.9 & 109 & 24.4 & 18.6 \\
\hline Standard deviation & 12 & 19.1 & 18.7 & 4.61 \\
\hline Minimum & 16 & 50 & 0 & 5 \\
\hline Maximum & 70 & 135 & 86 & 24 \\
\hline Skewness & -1.88 & -0.647 & 0.858 & -0.813 \\
\hline Kurtosis & 3.43 & 0.214 & 0.126 & 0.091 \\
\hline Shapiro-Wilk & $<.001$ & $<.001$ & $<.001$ & $<.001$ \\
\hline
\end{tabular}

Hypothesis 1. The perception of performance mediates the relationship between work effort and job satisfaction.

The three variables are correlated with each other, the Spearman correlation coefficients indicating average correlations (table no. 3 ).

Table no. 3. Spearman correlation coefficients - Effort, Performance and Satisfaction

\begin{tabular}{|l|l|r|r|r|}
\hline & & Work effort & Performance & Satisfactio \\
\hline \multirow{3}{*}{ Work effort } & Spearman's rho & - & \multicolumn{2}{|c|}{} \\
\cline { 2 - 3 } & p-value & - & \\
\hline \multirow{2}{*}{ Performance } & Spearman's rho & 0.644 & - \\
\cline { 2 - 4 } & p-value & $<.001$ & - & - \\
\cline { 2 - 4 } & Spearman's rho & 0.493 & 0.636 & - \\
\cline { 2 - 4 } & p-value & $<.001$ & $<.001$ & - \\
\hline
\end{tabular}


The correlation between Work Effort and Satisfaction is slightly weaker (Spearman's rho correlation coefficient $=0.493$ ), an additional reason to consider that the variable Performance (as perceived by participants) mediates the relationship between the other two variables.

The indirect effect $(\mathrm{a} \times \mathrm{b})$ represents only a part of the total effect $(55.5 \%$, higher than the direct effect), and the result is statistically significant, so we are talking about a partial mediation (table no. 4). In other words, we could consider that the direct relationship between effort and job satisfaction itself is weaker, as the perception of performance mediates the direct effect.

Table no. 4. Performance, mediator of effort - job satisfaction

\begin{tabular}{|l|l|r|r|r|r|r|}
\hline \multicolumn{2}{|c|}{ Effect } & Estimate & \multicolumn{1}{c|}{ SE } & \multicolumn{1}{c|}{ Z } & p & $\begin{array}{c}\text { \% } \\
\text { Mediation }\end{array}$ \\
\hline Indirect & $\mathrm{a} \times \mathrm{b}$ & 0.1103 & 0.016 & 6.89 & $<.001$ & 55.5 \\
\hline Direct & $\mathrm{c}$ & 0.0884 & 0.0222 & 3.99 & $<.001$ & 44.5 \\
\hline Total & $c+a \times b$ & 0.1986 & 0.0186 & 10.65 & $<.001$ & 100 \\
\hline
\end{tabular}

Hypothesis 2. Burnout moderates the relationship between effort and perception of performance.

We assume that this relationship is moderation, not mediation, as we did not find a direct influence of the effort in the sense of perseverance, direction and intensity, on burnout, but we consider that the relationship between effort and perception of performance is influenced by the burnout phenomenon (table no. 5 ; figure no. 2 ).

Table no. 5. Burnout, moderator of the relationship Effort - Perceived Performance

\begin{tabular}{|l|r|r|r|r|}
\hline & Estimate & \multicolumn{1}{|c|}{ SE } & \multicolumn{1}{c|}{$\mathbf{Z}$} & \multicolumn{1}{|c|}{ p } \\
\hline Work effort & 0.9216 & 0.06232 & 14.79 & $<.001$ \\
\hline Burnout & -0.3311 & 0.03964 & -8.35 & 0.004 \\
\hline Work effort x Burnout & -0.0116 & 0.00405 & -2.86 & $<1$ \\
\hline
\end{tabular}

The direct relationship between effort and performance is reduced for burnout's higher levels (figure no. 2). Therefore, the estimated slopes are 0.922 (average level), 1.138 (level decreased to -1 SD) and 0.705 (level increased to +1 SD), $p<0.001$ in all the three cases. 


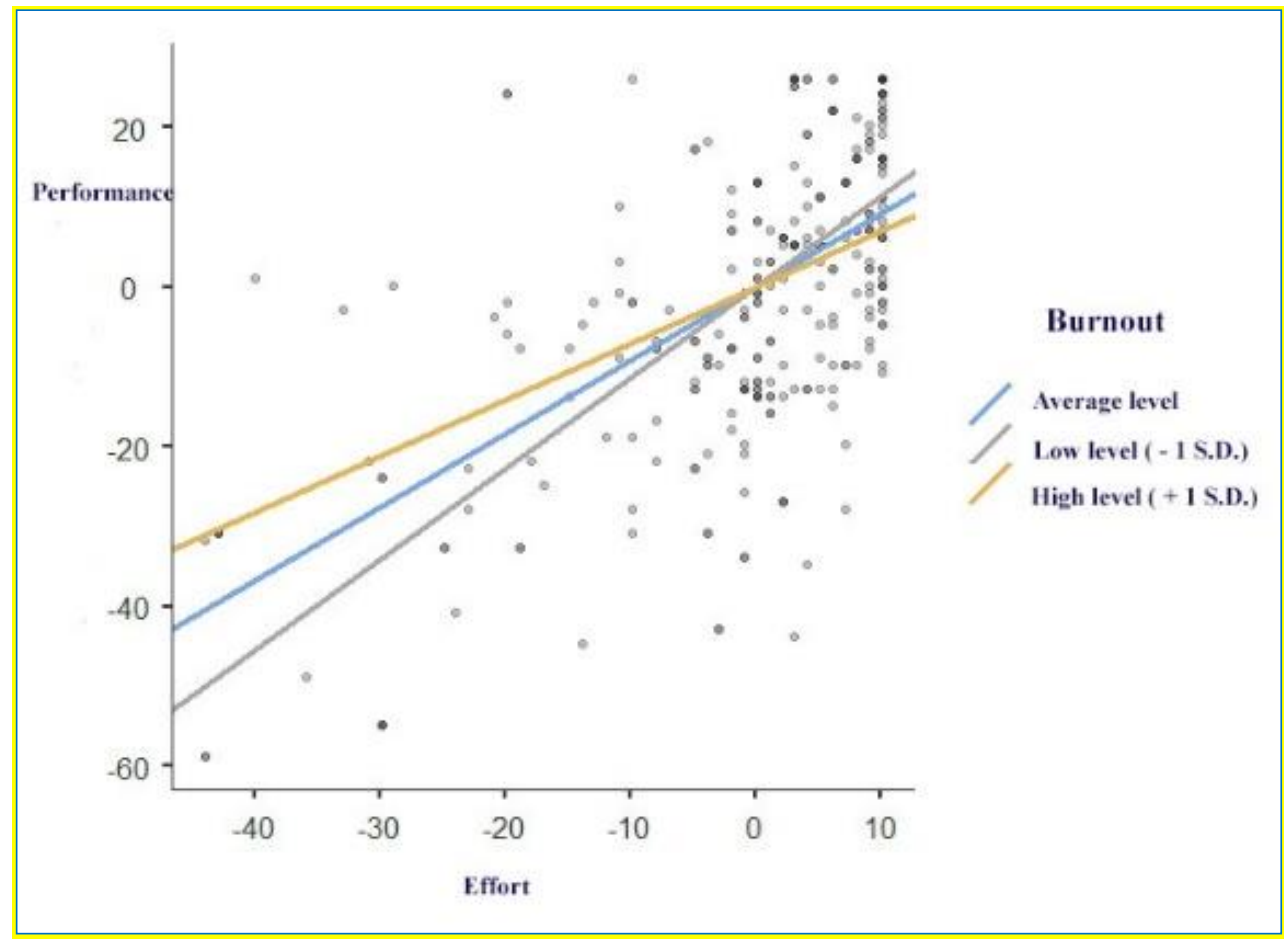

Figure no. 2. Burnout, moderator of the relationship Effort - Perceived Performance

Hypothesis 3. Burnout moderates the relationship between the perception of performance and the satisfaction obtained through the work itself.

Again, we assume that this relationship is moderating, not mediating, as we did not find a direct influence of performance perception on burnout, but we believe that burnout influences the relationship between perceived performance and job satisfaction itself (table no. 6, figure no. 3).

Table no. 6. Burnout, moderator of the relationship Performance - Job Satisfaction

\begin{tabular}{|l|r|r|r|r|}
\hline & Estimate & \multicolumn{1}{c|}{ SE } & \multicolumn{1}{c|}{ Z } & \multicolumn{1}{c|}{ p } \\
\hline Performance & 0.09259 & 0.00994 & 9.31 & $<.001$ \\
\hline Burnout & -0.10281 & 0.00991 & -10.37 & $<.001$ \\
\hline Performance x Burnout & -0.00251 & $6.37 \mathrm{E}-04$ & -3.94 & $<.001$ \\
\hline
\end{tabular}

The direct relationship between perceived performance and job satisfaction itself is reduced for higher levels of burnout (figure no. 3). 


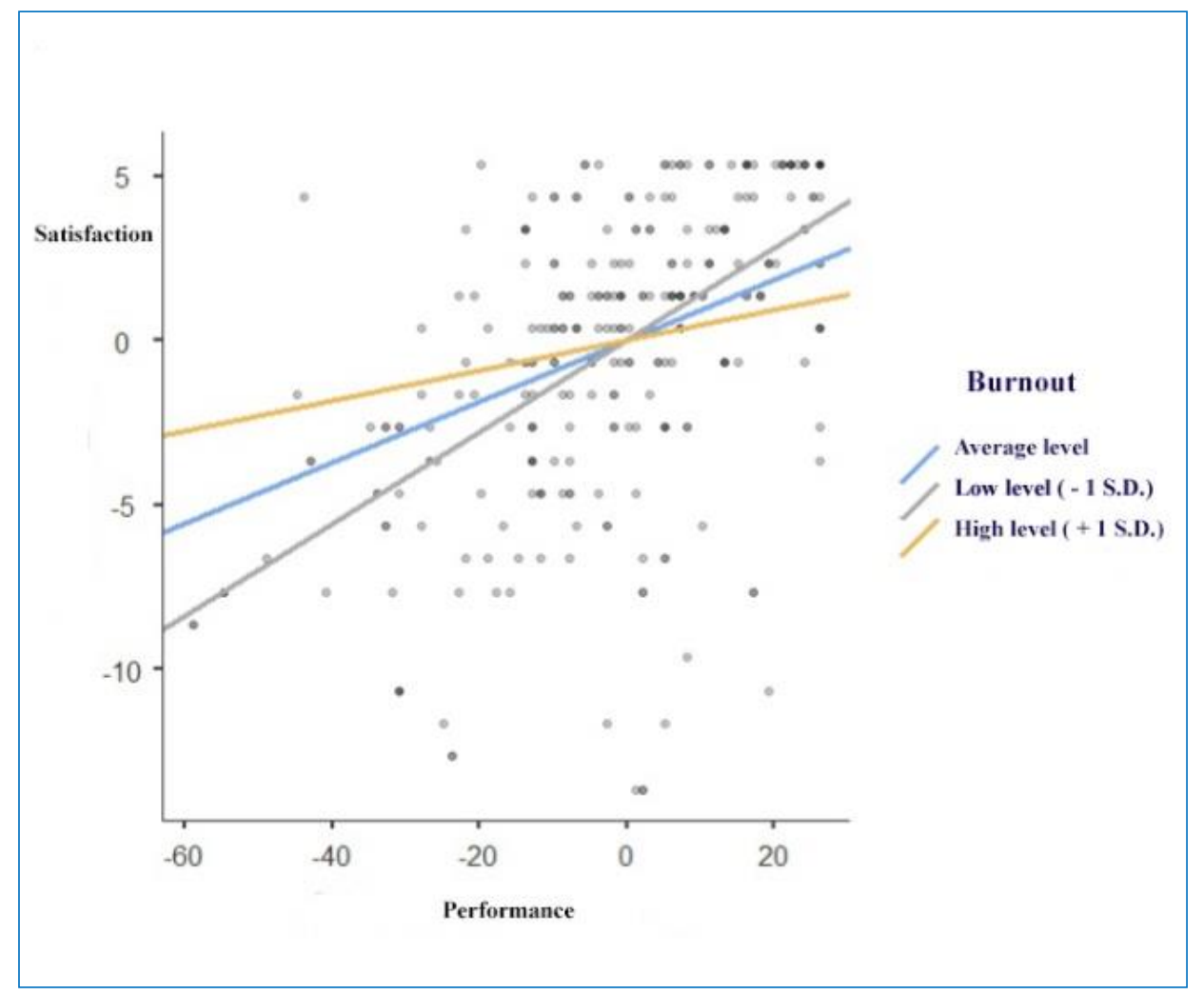

Figure no. 3. Burnout - moderator of the relationship Performance - Job Satisfaction

The estimated slopes are 0.0926 (average level), 0.1395 (level decreased to - 1 SD), 0.0457 (level increased to +1 SD), $\mathrm{p}<0.001$ in the first two cases and 0.009 in the third one. The influence of burnout as a moderating variable is even stronger in the case of this relationship compared to the previous relationship, getting closer to the lack of increase of the satisfaction level as a consequence for a higher performance.

Hypothesis 4. If participants hold a leadership position, then the level of burnout is lower than if the participants do not hold leadership positions.

Since the number of respondents managers and non-managers was not approximately equal, in order to test this hypothesis, we used a subgroup of 214 participants out of the total of 313 participants in our study (since there are 107 managers - employees or entrepreneurs, we randomly selected a group of 107 employees without management positions, out of the 206 who answered the questionnaire).

As in the case of the entire group of participants, the data is not normally distributed for any of the four considered variables (table no. 7). 
Table no. 7. Descriptive data for the four variables - small group of 214 participants

\begin{tabular}{|l|r|r|r|r|}
\hline & Work effort & Performance & Burnout & Satisfaction \\
\hline N & 214 & 214 & 214 & 214 \\
\hline Mean & 59.8 & 110 & 21.5 & 19 \\
\hline Standard deviation & 12.5 & 20.3 & 18.1 & 4.61 \\
\hline Minimum & 16 & 50 & 0 & 5 \\
\hline Maximum & 70 & 135 & 86 & 24 \\
\hline Skewness & -1.94 & -0.73 & 1.09 & -0.844 \\
\hline Kurtosis & 3.57 & 0.0521 & 0.848 & 0.0398 \\
\hline Shapiro-Wilk & $<.001$ & $<.001$ & $<.001$ & $<.001$ \\
\hline
\end{tabular}

For testing hypothesis 4 , we use the Mann-Whitney test (table no. 8).

Table no. 8. Mann-Whitney U Test - Burnout: Managers versus Non-managers

\begin{tabular}{|c|c|c|c|}
\hline & Mann-Whitney U & p & Rank-biserial correlation \\
\hline Burnout & 3222 & $<.001$ & -0.733 \\
\hline
\end{tabular}

The size of the effect is given by the rank-biserial correlation, so it is quite large. The test is statistically significant and indicates that the burnout level of managers is lower than that of non-managers (the average value of the burnout variable is 15.3 , with a standard deviation of 15.1 for managers and 27.7, respectively, with a standard deviation of 18.7 in the case of those without a management position).

\subsection{Discussions}

According to the first confirmed hypothesis, the perception of performance mediates the relationship between effort and satisfaction obtained through the work itself. Of course, the work effort seen as perseverance, direction and intensity leads to additional satisfaction in itself. However, the indirect relationship is also important, as there are cases where people make real efforts at work and performance is influenced by other aspects, such as inadequate technologies, unfavourable context, lack of talent, low self-image. In those cases, although one works with perseverance and dedication, job satisfaction may be a little reduced as a result of inferior results. Likewise, in cases where there is no dedication to work, it is possible that the satisfaction through the work itself can be quite high, as a result of better results, even if they were obtained accidentally.

Burnout is a moderator in the relationship between effort and perception of performance. Perseverance, direction and intensity of effort lead in principle to a higher appreciation of competence, adaptability and proactivity in performing individual, group or organizational tasks. However, this positive relationship is attenuated in the conditions in which people are subjected to pressures of professional overload combined with the underestimation by others of the individual's efforts. We consider it natural that, in conditions of emotional exhaustion, without enthusiasm and desire to get involved and with a tendency to underestimate the 
results of work, regardless of their level, the perception of performance is lower, even if the effort was a considerable one.

Burnout is also a moderator in the relationship between the perception of performance and the satisfaction obtained through the work itself. The data indicated that the effect of the burnout phenomenon is even greater than in the case of the previous relationship. Depleted by resources, with attitudes such as lack of involvement and lack of enthusiasm and the tendency to evaluate their work in a negative way, people affected by the burnout phenomenon no longer respond with the same job satisfaction when their performance increases. The relationship between performance and satisfaction remains a positive one even in conditions of high burnout, but it is much weaker.

According to our study, managers and entrepreneurs show a lower level of burnout than those who do not hold management positions. Although we found this idea in the literature, it is a controversial issue, as there is an objective element in this equation, namely that the leadership function comes bundled with a busier schedule. On the other hand, other authors appreciated that the coping mechanisms (concept introduced by the psychologists to describe all the individual's cognitive and behavioural efforts made in order to deal successfully with a difficult situation) are the ones that matter a lot in the way each of us relates to the overcrowding of activities and, in general, people with leadership positions manage in many situations to adapt better to situations and not to react negatively when a stressor occurs.

\section{Conclusions}

The creator of performance is the man seen as a source of effort and a beneficiary of satisfaction. In the modern world, when we talk about the relationship effort-performancesatisfaction we cannot ignore the phenomenon of burnout that actively moderates the relationship between the three concepts. In other words, the appearance of the burnout phenomenon diminishes the other positive relationships.

All four hypotheses were confirmed and thus the model was validated, based on the data collected by us. It turned out that the perception of performance mediates the relationship between effort and job satisfaction itself, and burnout is moderating both in the relationship between effort and performance perception, and in the relationship between performance perception and job satisfaction itself. Also, according to the literature, it has been found that management functions are associated with a lower level of burnout than others, a greater power in decision-making means an increased ability to detach from problems, even if the investment in work is appreciable.

As revealed by Ajzen's (2011) research, as well as in ours, effort, performance and job satisfaction are always filtered by attitudes, subjective norms and perceptions about the real possibility of influencing the level of performance. We consider that our result does not necessarily contradict the one obtained by Brown and Peterson (1994), according to which the effort made in work has a direct effect on satisfaction, without being mediated by performance, since we operated with different constructs. Thus, the construct analysed by us is not the real performance, measured objectively, but the performance perceived by each one for itself.

Regarding the role of moderator of the burnout phenomenon, we found it interesting to look at the relationship between variables from this angle. As Woo, Park, and Kim (2017) found 
that job satisfaction is a moderator in the relationship between burnout and productivity, we looked at whether burnout plays a moderator in the effort-perception relationship over performance, as well as in the perception relationship over job performance-satisfaction.

Even if the model proposed in this paper has been validated, certain limitations of the research should be taken into account. First of all, we mention the sampling method used (unlikely), based on availability and volunteering criteria. As such, representativeness cannot be achieved or estimated, and the results cannot be generalized to the population. We cannot control the effect of series of confounding variables, that we did not take into account in our research. The leadership style used in the organizations to which the respondents belong may cause some differences; likewise, the balance between personal and professional life that the study participants have.

According to Potter's (2005) observation, participants with leadership positions have a lower level of burnout than those without such functions. This aspect deserves further investigation, as we analysed the perception of burnout only in the case of some people who expressed their willingness to complete our questionnaire.

Moreover, the data collection period largely overlapped with the period of emergency in Romania, as a result of the COVID-19 situation. Some of the participants became more available for our research as a result of this situation, some felt a higher level of stress than usual, some reported that they completed quite a few online questionnaires during this period, etc., and these influences could not be quantified. One direction of future research is to resume the study after a period, using the same questionnaire, on another group of participants, similar in structure, so we can observe the effect of the pandemic on our results, by comparing the two independent groups.

Although the number of 313 participants in the study is not a really small one in order to perform statistical processing, it would be necessary to increase this number in order to make comparisons between different fields of activity.

Also, since the data were distributed non-parametrically (sometimes obviously from indices of symmetry and vaulting, and in the case of performance only by the Shapiro-Wilk test), non-parametric tests were mainly used that diminished the statistical power.

The question remains whether performance determines job satisfaction or whether satisfaction is what influences performance, given that there are factors that inter condition. Beyond the debates, the self-evaluation of the participants cannot be confused with the real level of performance. Therefore, another future research direction aims at designing an experimental design, through which the variables can be observed as actions / sets of behaviours/concrete results in terms of performance at work. Later working with both constructs, the performance given by the results obtained within the organization and the performance as it is perceived by each one, we could extend and modify the proposed model.

Finally: we want to emphasize once again the central idea from which we started, namely that in order to have superior performance at the organizational level, employees need to be more satisfied. Given our model managers could consider at least three directions to increase job satisfaction:

- recruitment techniques, so that the right people are in right place, people willing to make an effort in the sense of perseverance, direction and intensity. 
- techniques through which employees develop their coping mechanisms so as to better cope with stressors and burnout, when necessary.

- motivation techniques, in order to increase the level of satisfaction based on emphasizing the positive evaluation of performance.

\section{References}

Ajzen, I., 2011. Job satisfaction, effort, and performance: A reasoned action perspective. Contemporary Economics, 5(4), pp.32-43.

Bakker, A. B., 2009. The crossover of burnout and its relation to partner health. Stress and Health, 25(4), pp.343-353.

Bakotić, D., 2016. Relationship between job satisfaction and organisational performance. Economic Research-Ekonomska Istraživanja, 29(1), pp.118-130.

Bandura, A., 1986. Social foundations of thought and action: a social cognitive theory. New Jersey: Prentice Hall.

Bourguignon, A., 1997. Sous les paves la plage... ou les multiples fonctions du vocabulaire comptable: l'exemple de la performance. Comptabilité - Contrôle - Audit, 3(1), pp.89-101.

Brown, S. P. and Peterson, R. A., 1994. The effect of effort on sales performance and job satisfaction. Journal of Marketing, 58(2), pp.70-80.

Burke, R. J. and Greenglass, E. R., 2001. Hospital restructuring, work-family conflict and psychological burnout among nursing staff. Psychology \& Health, 16(5), pp.583-594.

Campbell, J. P., McCloy, R. A., Oppler, S. H. and Sager, C. E., 1993. A Theory of Performance. In: N. Schmitt and W.C. Borman eds., 1993. Personnel Selection in Organizations. San Francisco: Jossey-Bass.

Christen, M., Iyer, G. and Soberman, D., 2006. Job Satisfaction, Job Performance, and Effort: A Reexamination Using Agency Theory. Journal of Marketing, 70(1), pp.137-150.

De Cooman, R., De Gieter, S., Pepermans, R., Jegers, M. and Van Acker, F., 2009. Development and Validation of the Work Effort Scale. European Journal of Psychological Assessment, 25(4), pp.266-273.

Freudenberger, H. J., 1980. BurnOut: The High Cost of High Achievement. New York: Anchor Press.

Gorji, M., 2011. The Effect of Job Burnout Dimension on Employees' Performance. International Journal of Social Science and Humanity, 1(4), pp.243-246.

Griffeth, R. W., Hom, P. W. and Gaertnert, S., 2000. A meta-analysis of antecedents and correlates of employee turnover: Update, moderator tests, and research implications for the next millennium. Journal of Management, 26(3), pp.463-488.

Griffin, M. A., Neil, A. and Parker, S. K., 2007. A new model of work role performance: Positive behavior in uncertain and interdependent contexts. Academy of Management Journal, 50(2), pp.327-347.

Judge, T. A., Thoresen, C. J., Bono, J. E. and Patton, G. K., 2001. The Job Satisfaction-Job Performance Relationship: A Qualitative and Quantitative Review. Psychological Bulletin, 127(3), pp.376-407. 
Karatepe, O. M., Uludag, O., Menevis, I., Hadzimehmedagic, L. and Baddar, L., 2006. The effects of selected individual characteristics on frontline employee performance and job satisfaction. Tourism Management, 27(4), pp.547-560.

Kuok, A. and Taormina, R. J., 2017. Work Engagement: Evolution of the Concept and a New Inventory. Psychological Thought, 10(2), pp.262-287.

Leatz, C. A. and Stolar, M. W., 1993. Career Success: Personal Stres - How to stay healthy in a high-stress environment. New York: McGraw-Hill.

Locke, E. A. and Latham, G. P., 1985. The application of goal setting to sports. Journal of Sport Psychology, (7), pp.205-222.

Luthans, F., 1998. Organisational Behaviour. 8th ed. Boston: Irwin McGraw-Hill.

Maslach, C., Jackson, S. E. and Leiter, M. P., 1997. Maslach Burnout Inventory: Third edition. In: C.P. Zalaquett and R.J. Wood eds., 1997. Evaluating stress: A book of resources. Lanham: Scarecrow Education, pp.191-218.

Maslach, C., Schaufeli, W. B. and Leiter, M. P., 2001. Job Burnout. Annual Review of Psychology, 52(1), pp.397-422.

Maslach, C. and Jackson, S. E., 1982. Burnout in the health professions: A social psychological analysis. In: G.S. Sanders and J. Suls eds., 1982. Social Psychology of Health and Illness. London: Lawrence Erlbaum Associates, pp.227-251.

Motowidlo, S. J., Borman, W. C. and Schmit, M. J., 1997. A theory of individual differences in task and contextual performance. Human Performance, 10(2), pp.71-83.

Motowidlo, S. J. and Scotter, J. R., 1994. Evidence That Task Performance Should Be Distinguished From Contextual Performance. Journal of Applied Psychology, 79(7), pp.475-480.

Posada, M., Martín-Sierra, C. and Perez, E., 2017. Effort, Satisfaction and Outcomes in Organisations. Journal of Artificial Societies and Social Simulation, 20(9), [online] Disponibil la <http://jasss.soc.surrey.ac.uk/20/2/9.html> [Accessed 4 March 2020].

Potter, B. A., 2005. Overcoming job burnout: how to renew enthusiasm for work. Berkeley: Ronin Publishing.

Pushpakumari, M. D., 2008. The Impact of Job Satisfaction on Job Performance: An Empirical Analysis. Psychology, 9(1), [online] Available at: <http://wwwbiz.meijou.ac.jp/SEBM/ronso/no9_1/08_PUSHPAKUMARI.pdf> [Accessed 12 March 2020].

Research Central, n.d. Listă de teste - versiunea în limba română a International Personality Item Pool (IPIP). [online] Available at: <http://www.researchcentral.ro/ index.php?action=listateste $>$ [Accessed 2 March 2020].

Roe, R. A., 1999. Work performance: A multiple regulation perspective. International Review of Industrial and Organizational Psychology, 14, pp.231-335.

Shimazu, A., Schaufeli, W. B., Kamiyama, K. and Kawakam, N., 2014. Workaholism vs. Work Engagement: the Two Different Predictors of Future Well-being and Performance. International Journal of Behavioral Medicine, 22(1), pp.18-23.

Snir, R. and Harpaz, I., 2011. Beyond workaholism: Towards a general model of heavy work investment. Beyond Workaholism: Towards a General Model of Heavy Work Investment. 22, pp.232-243. 
Snir, R. and Zohar, D., 2008. Workaholism as Discretionary Time Investment at Work: An Experience-Sampling Study. Applied Psychology, 57(1), pp.109-127.

Sonnentag, S. and Frese, M., 2002. Performance concepts and performance theory. Psychological management of individual performance. Chichester: John Wiley \& Sons.

Spector, P. E., 1997. Job satisfaction: Application, assessment, causes, and consequences. Thousand Oaks: SAGE Publications.

Woo, H., Park, S. and Kim, H., 2017. Job satisfaction as a moderator on the relationship between burnout and scholarly productivity among counseling faculty in the U.S. Asia Pacific Education Review, 18(4), pp.573-583.

Van Beek, I., Taris, T. W., Schaufeli, W. B. and Brenninkmeijer, V., 2013. Heavy work investment: its motivational make-up and outcomes. Journal of Managerial Psychology, 29(1), pp.46-62. 